\title{
Study on Level of Knowledge and Attitude of Farmers towards System of Wheat Intesification (SWI) Technology in Samastipur District of Bihar, India
}

\author{
Shweta Kumari and Satya Prakash* \\ Department of Extension Education, Dr. Rajendra Prasad Central Agricultural University, \\ Pusa, Samastipur, Bihar-848125, India \\ *Corresponding author
}

\begin{tabular}{|l|}
\hline Ke y w or d s \\
SWI, Climate \\
change, Climate- \\
smart farming, \\
Knowledge, \\
Attitude
\end{tabular}

A B S T R A C T
Wheat (Triticum aestivum $\mathrm{L}$ ) stands second in grain production in the world and most widely cultivated food crop. Agriculture in the post-green revolution era postponed the near seen dangerous cloud of the great famine due to population explosion in the third world where there was very low growth rate of crop production as compared to population growth. At initial decades of 21st century, another probability of great famine appeared in the world due to long drought in tropical and subtropical and at the same time it appeared more dangerously because of the contemporary climate change threat. System of Wheat Intensification (SWI) which is based on the principles of System of Rice Intensification (SRI) is a new wheat cultivation technique which might act as a significantly new weapon as a part of climate-smart farming. It is one of the promising technologies to increase productivity which ultimately contributes to the household level food security of marginal farmers. The present study was conducted in Samastipur district of Bihar state in India. 4 panchayats (Thahara, Morsand, Indarwara, Sarangpur) were selected from 2 blocks of Samastipur (Pusa and Morwa) based on assumption that these blocks have the largest number of adopters of SWI technology. The total number of respondents (beneficiaries and non-beneficiaries) selected for the study was 60 . Frequency, percentage, arithmetic mean and standard deviation were used as the statistical tools to measure the level of knowledge of the respondents regarding SWI technologies and their attitude towards SWI methods. As a result, it was found that $13.33 \%$ of respondents have low level of knowledge among adopters whereas $60 \%$ of respondents i.e. majority have low level of knowledge among non-adopters. Besides, 50 percent adopters had favourable attitude and 16.67 percent had unfavourable attitude. While in case of non-adopters categories maximum percentage of respondents had undecided their attitude towards SWI technology i.e. 43.33 percent, followed by 40 percent had unfavourable attitude and 16.67 percent had favourable attitude. 


\section{Introduction}

Wheat stands second in grain production in the world and most widely cultivated food crop. The Global area of wheat cultivation was $218.5 \mathrm{~m}$ ha compared to $156 \mathrm{~m}$ ha under rice (FAO, 2014). In India, wheat is second important staple food crop (DWR, 2012) after rice. India has now be-come the second largest producer of wheat in the world with a production of $93.5 \mathrm{~m} \mathrm{t}$ (13.6\% of total world wheat production) from $29.7 \mathrm{~m}$ ha area with average productivity of $3.15 \mathrm{t} / \mathrm{ha}$ (FAO, 2014) The major wheat producing states are Uttar Pradesh, Punjab, Haryana, Madhya Pradesh, Rajasthan, Bihar, Maharashtra, Gujarat, West Bengal and Uttarakhand. Introduction of semi dwarf varieties increased the consumption of fertilizer per unit area tremendously and promoted mechanization in agriculture. In one side it increased the overall production and postponed the near seen dangerous cloud of the great famine due to population explosion in the third world where there was very low growth rate of crop production as compared to population growth. However in long term advantages of green revolution were taken only by developed country and farmers who were fortified by irrigation, mechanization and high agro inputs. But at initial decades of 21st century another probability of great famine appeared in the world due to long drought in tropical and subtropical and at the same time it appeared more dangerously because most of the developed countries adopted policies of using consumable grains into bio fuel production. Therefore, another very serious initiative was needed to increase the productivity of major crop in the very marginal land with low input and sustainable way. In this context, in many parts of the third world System of Wheat Intensification created government attention. Among winter crops, it contributes nearly about 49 per cent of food grains. In Bihar, wheat is grown about 2.1 million hectare with a production and productivity of 4 million tonnes and 1.95 tonnes per hectare, respectively. Wheat has been the staple food of the majority of population of Bihar. It forms the very basis of foods security system of our state. Wheat production of our state has maintained an uprising trend despite of various unpredictable situations of weather uncertainties. In spite all of these achievements, the productivity picture of wheat in Bihar $(24 \mathrm{q} / \mathrm{ha})$ is not very encouraging, rather quite low when compared with national wheat productivity $(31.4 \mathrm{q} / \mathrm{ha})$. In Bihar rice-wheat culture is practiced in $80 \%$ of arable land area. A growing movement has emerged during the past few decades to question the role of the agricultural establishment in promotion practices that contribute to the social problems. Innovative agricultural practices not only address many environmental and social concerns, but also offer economically viable opportunities for growers, labourers, consumers, policy makers and many others in the entire food production system.

There is a need to intensify the cultivation of crops by using optimum input through BMP (Best Management Practices) for resource conservation. There is a need for adoption of intensive agricultural practices for increasing the productivity in wheat to ensure food security for the people. Wheat intensification is a new concept and goes with the system of rice intensification (SRI) principle. In case of SWI, all agronomic principles of SRI are put into practices and integrated with package of practices of wheat crop. The technology which has high potentiality to provide high wheat yield per drop of water and per $\mathrm{kg}$ of agricultural inputs (fertilizer, seed etc.) and application of other SRI principle to wheat crop, is known as system of wheat intensification (SWI). Adoption of this technology can increase the productivity of wheat by more than 2 times (Uphoff et al., 2011). The method is about managing the 
crop, soil and nutrients to promote a vibrant soil system that, in turn, pro-motes larger root systems. Therefore, System of wheat intensification (SWI) is an adoption of technique used in the system of rice intensification (SRI) methodology of increasing the productivity of crops by changing the management of plant, soil, water and nutrients while reducing external inputs use. Fortunately, experience with the system of rice intensification developed in Madagascar over 30 years ago by father Hendrei de Laulani'e offers some ways to make production system, cost effective, efficient and of increase climate secure. The merit of system have now been demonstrated worldwide especially rice growing countries of Asia and many other countries as well as its concept and practices are now being extended beyond irrigated rice to wheat, ragi, sugarcane, beans and other crops (Thapa et al., 2011). System of wheat intensification has been tested as an innovative approach to increase productivity and being practiced in India, China, Ethiopia, Poland and USA. SRI has already been tested and evaluated by several NGOs, but System of wheat intensification is still a new technology for wheat cultivation in India. The main objective of this trail is to compare the yield from traditional practice with that from SWI (Khadka et al., 2011).

The prevalent system of wheat cultivation requires more chemical fertilizers and nearly $120-180 \mathrm{~kg}$ of seed per hectare. SWI use only $20-30 \mathrm{~kg}$ improved seed per hectare. $15-20 \mathrm{~cm}$ spacing between row to row and plant to plant, use of manure and organic seed treatment ensure higher yield. Sufficient spacing between the plants and sowing of two seed grains at one point facilitates desired moisture, aeration, nutrition and light to the crop roots. This helps faster growth of plants. Only 2-3 times irrigation and weeding through conoweeder save times and expenses on labour.
SWI is primarily based on these two principles of crop production first principle of root development and second principle of intensive care. System of wheat intensification (SWI) is one of the promising technologies to increase productivity which ultimately contributes to the household level food security of marginal farmers. It might act as a significant new technology towards the domain of climatesmart agriculture.

\section{Objectives of the study}

The main objective of study is to analyse the level of ideas of SWI method and attitudes of the respondent farmers towards SWI in Samastipur district of Bihar state in India. The specific objectives are to:

Assess the level of knowledge about SWI of adopters as well as non adopters.

Ascertain attitude of selected respondents towards SWI technology.

\section{Materials and Methods}

The study was conducted in Samastipur district of Bihar state. Samastipur district was selected purposively because the researcher's university/institute is located exactly here and thus it would be easily approachable. Moreover, the researcher is well acquainted with the culture, social customs and situations prevailed in this district. 2 specific blocks viz. Pusa and Morwa blocks have been selected for the study purpose based on assumption that the block has the largest number of adopters of SWI technology. 2 Panchayats viz. Thahara and Morsand were selected among 13 Panchayats of Pusa block and 2 Panchayats viz. Indarwara and Sarangpur were selected among 18 Panchayats of Morwa block. A complete list of the adopters who have undergone through cultivation of wheat through SWI technology was obtained from 
District Agricultural Officer Samastipur. 15 adopters and 15 non-adopters respondents from each of 2 blocks were purposively selected. Therefore 30 beneficiary and 30 nonbeneficiary respondents were selected. So, the total number of beneficiaries and nonbeneficiaries selected for the study was 60 .

Only the primary data is used and that was collected through survey. Data has been collected through preparation of wellstructured interview schedule. For assessing the level of knowledge of adopters as well as non-adopters regarding SWI technology, knowledge index was used. Knowledge index $=$ (obtained knowledge score/highest knowledge score) $\mathrm{x} 100$. The adopters as well as non-adopters are placed in low, medium and high categories according to their score. The schedule prepared for measuring the attitude of the respondents consists of 10 statements and each statement was assessed on a 5-point Likert-type scale in terms of strongly agrees, agree, undecided, disagree and strongly disagree responses respectively. The attitude of the respondents was further categorized as favourable, undecided and unfavourable by working out arithmetic mean and standard deviation (S.D). If the obtained score is below (Mean-S.D), that respondent is placed in unfavourable category. If the score is between (Mean-S.D.) to (Mean+S.D.), that respondent is placed in undecided category and if the score is above (Mean+S.D.), the respondent is placed in favourable category.

\section{Results and Discussion}

Level of Knowledge of both Adopter and Non-adopter Respondents

To assess the level of knowledge on SWI technology, a knowledge test was specially developed for the purpose, which constituted of 19 questions with correct answers getting score of 1 and incorrect answer getting a score of 0 , the knowledge was administered to both the samples of respondents the adopters and non adopters. By using the knowledge index formula, the knowledge score of all the 30 adopters and 30 non-adopters were put in a statistical process to find out the arithmetic mean and standard deviation, which eventually were used to estimate frequency and percentages.

As per the table 2, 50 per cent adopters had medium level of knowledge and 36.67 per cent adopters had high level of knowledge. There were only 13.33 per cent of adopters who had low level of knowledge. While in case of non-adopters 30 per cent had medium level of knowledge and 60 percent had low level of knowledge. The non-adopters having high level of knowledge were only 10 per cent. It indicates that majority of adopter were having medium level of knowledge followed by high level of knowledge. While in case of non-adopters majority of them had low level of knowledge followed by medium level of knowledge.

Table.1 Selection of the respondents

\begin{tabular}{|c|c|c|c|c|c|}
\hline $\begin{array}{c}\text { SI. } \\
\text { No. }\end{array}$ & $\begin{array}{c}\text { Name of the } \\
\text { block }\end{array}$ & $\begin{array}{c}\text { Name of the } \\
\text { selected villages }\end{array}$ & $\begin{array}{c}\text { Total number } \\
\text { of the } \\
\text { respondents }\end{array}$ & $\begin{array}{c}\text { Selected } \\
\text { adopters }\end{array}$ & $\begin{array}{c}\text { Selected } \\
\text { non- } \\
\text { adopters }\end{array}$ \\
\hline $\mathbf{1 .}$ & Pusa & Thahara & 15 & 8 & 7 \\
\hline $\mathbf{2 .}$ & Morwa & Morsand & 15 & 7 & 8 \\
\hline & & Indrawara & 15 & 7 & 8 \\
\hline
\end{tabular}


Table.2 Frequency and Percentage distribution of adopters and non-adopters with respect to their level of knowledge

\begin{tabular}{|c|c|c|c|c|c|}
\hline \multirow{2}{*}{$\begin{array}{c}\text { S1. } \\
\text { No. }\end{array}$} & \multirow{2}{*}{ Category } & \multicolumn{2}{|c|}{ Adopters $(\mathbf{n = 3 0})$} & \multicolumn{2}{c|}{ Non-adopters $(\mathbf{n = 3 0})$} \\
\cline { 3 - 6 } & & Frequency & Percentage & Frequency & Percentage \\
\hline 1. & Low & 4 & 13.33 & 18 & 60 \\
\hline 2. & Medium & 15 & 50 & 9 & 30 \\
\hline 3. & High & 11 & 36.67 & 3 & 10 \\
\hline & Total & 30 & 100 & 30 & 100 \\
\hline
\end{tabular}

Table.3 Frequency and percentage distribution of various components of knowledge on SWI technology of the adopters

\begin{tabular}{|c|c|c|c|}
\hline \multirow{2}{*}{$\begin{array}{c}\text { Sl. } \\
\text { No. }\end{array}$} & \multirow[t]{2}{*}{ Components of knowledge of SWI technology } & \multicolumn{2}{|c|}{ Adopters $(\mathrm{n}=30)$} \\
\hline & & Frequency & Percentage \\
\hline A. & Pre sowing technology & & \\
\hline 1. & Type of land required for wheat crop production & 24 & 80 \\
\hline 2. & No. of ploughing required for wheat production & 25 & 83.33 \\
\hline 3. & Manuring required for wheat cultivation & 21 & 70 \\
\hline 4. & Requirement of zero tillage & 26 & 86.66 \\
\hline B. & Seed and seed treatment & & \\
\hline 5. & Selection of seed variety & 23 & 76.66 \\
\hline 6. & What is optimum time for sowing & 25 & 83.33 \\
\hline 7. & Seed rate in $\mathrm{kg} / \mathrm{hectare}$ & 21 & 70 \\
\hline C. & Irrigation management & & \\
\hline 8. & Optimum no. of irrigation required for wheat production & 23 & 76.66 \\
\hline 9. & Days of interval required for irrigation & 24 & 80 \\
\hline 10. & Stage of critical in which irrigation required & 18 & 60 \\
\hline D. & Plant Protection Measures & & \\
\hline 11. & $\begin{array}{l}\text { Mention the name of disease and doses of chemical use } \\
\text { for disease control }\end{array}$ & 20 & 66.66 \\
\hline 12. & Harvesting time of early mid and late variety & 22 & 73.33 \\
\hline 13. & Seed treatment with fungicide & 19 & 63.33 \\
\hline E. & Fertilizer management & & \\
\hline 14. & Application of fertilizer in wheat production & 24 & 80 \\
\hline F. & Crop management & & \\
\hline 15. & $\begin{array}{l}\text { Row to row space required for wheat production through } \\
\qquad \text { SWI }\end{array}$ & 22 & 73.33 \\
\hline 16. & Inter-cultural operation & 21 & 70 \\
\hline 17. & Herbicide used in wheat crop & 19 & 63.33 \\
\hline 18. & $\begin{array}{l}\text { Use of chemical and other materials during storage of } \\
\text { wheat grains for preventing of pest infestation }\end{array}$ & 24 & 80 \\
\hline \multirow[t]{2}{*}{19.} & Name of chemical for fumigation & 18 & 60 \\
\hline & Overall \% knowledge & & 73.51 \\
\hline
\end{tabular}


Table.4 Frequency and percentage distribution of various components of knowledge on SWI technology of the non-adopters

\begin{tabular}{|c|c|c|c|}
\hline \multirow[t]{2}{*}{ Sl. No. } & \multirow[t]{2}{*}{ Components of knowledge of SWI technology } & \multicolumn{2}{|c|}{ Adopters $(n=30)$} \\
\hline & & Frequency & Percentage \\
\hline A. & Pre sowing technology & & \\
\hline 1. & Type of land required for wheat crop production & 15 & 50 \\
\hline 2. & No. of ploughing required for wheat production & 12 & 40 \\
\hline 3. & Manuring required for wheat cultivation & 9 & 30 \\
\hline 4. & Requirement of zero tillage & 10 & 33.33 \\
\hline B. & Seed and seed treatment & & \\
\hline 5. & Selection of seed variety & 17 & 56.66 \\
\hline 6. & What is optimum time for sowing & 13 & 43.33 \\
\hline 7. & Seed rate in $\mathrm{kg} / \mathrm{hectare}$ & 15 & 50 \\
\hline C. & Irrigation management & & \\
\hline 8. & $\begin{array}{l}\text { Optimum no. of irrigation required for wheat } \\
\text { production }\end{array}$ & 18 & 60 \\
\hline 9. & Days of interval required for irrigation & 13 & 43.33 \\
\hline 10. & Stage of critical in which irrigation required & 12 & 40 \\
\hline D. & Plant Protection Measures & & \\
\hline 11. & $\begin{array}{l}\text { Mention the name of disease and doses of chemical } \\
\text { use for disease control }\end{array}$ & 9 & 30 \\
\hline 12. & Harvesting time of early mid and late variety & 12 & 40 \\
\hline 13. & Seed treatment with fungicide & 11 & 36.66 \\
\hline E. & Fertilizer management & & \\
\hline 14. & Application of fertilizer in wheat production & 14 & 46.66 \\
\hline F. & Crop management & & \\
\hline 15. & $\begin{array}{l}\text { Row to row space required for wheat production } \\
\text { through SWI }\end{array}$ & 12 & 40 \\
\hline 16. & Inter-cultural operation & 7 & 23.33 \\
\hline 17. & Herbicide used in wheat crop & 8 & 26.66 \\
\hline 18. & $\begin{array}{l}\text { Use of chemical and other materials during storage } \\
\text { of wheat grains for preventing of pest infestation }\end{array}$ & 5 & 16.66 \\
\hline 19. & Name of chemical for fumigation & 7 & 23.33 \\
\hline & Overall \% knowledge & & 38.42 \\
\hline
\end{tabular}

Table.5 Frequency and percentage distribution of adopters and non-adopters according to their attitude towards SWI technology

\begin{tabular}{|c|c|c|c|}
\hline Categories of respondents & \multicolumn{3}{|c|}{ Attitude towards SWI method of wheat } \\
\hline & Favourable & Undecided & Unfavourable \\
\hline Adopters $(\mathbf{N = 3 0})$ & $15(50)$ & $10(33.33)$ & $5(16.67)$ \\
\hline Non-adopters $(\mathbf{N}=\mathbf{3 0})$ & $05(16.67)$ & $13(43.33)$ & $12(40)$ \\
\hline
\end{tabular}


As per the table 3, the questions were correctly answered by 73.51 percent of adopters, while the range varies from as low as 60 percent to as high as 86.66 percent. 60 to 86.66 percent adopters were well aware about general info and technical knowhow of SWI technology. Moreover, majority of the respondents were well aware about the technology.

Table 4 reveals that the questions were correctly answered by 38.42 percent of nonadopters, while they ranged from as low as 16.66 percent to as high as 60 percent.

\section{Attitude of selected respondents towards SWI}

Based on the responses given by the adopters to each of the statements, the total score of each respondent was calculated. On the basis of total score obtained, the respondents were categorized by working out frequency and percentage into 5 groups viz. strongly agree, agree, undecided, disagree and strongly disagree.

This table 5 shows that 50 percent adopters had favourable attitude, followed by 33.33 percent adopters had undecided their attitude and 16.67 percent had unfavourable attitude.

While in case of non-adopters categories maximum percentage of respondents had undecided their attitude towards SWI technology i.e. 43.33 percent, followed by 40 percent had unfavourable attitude and 16.67 percent had favourable attitude.

\section{Recommendations}

The social science research leading to degree has its own limitation in terms of time and resources. This study also fall in the category of social sciences faced a lot of constraints in generalizing the findings beyond the purview of the research areas. However, what emerged out of this study that its findings may be taken as a point of reference to start of drive for improving the level of knowledge as well as attitude of the peasants especially in those components where a lot still seems to be covered.

SWI is a fresh technical intervention of increasing the productivity of crops by changing the management of plant, soil, water and nutrients while reducing external inputs. It is one of the promising technologies to increase productivity of wheat which ultimately contributes to the household level food security of marginal farmers as well as the common mass. The sharpness and productivity of finding depends on selective use of variables responsible for affecting the level of knowledge of farmers about SWI as well as their attitude towards SWI. The variables which were found accountable for these should be profitable manipulated. Some of the variables which were found within manageable range of the farmers and some are to be induced by change promoters. It is quite evident from the results of the statistical analysis that there is a significant knowledge gap between the adopters and non-adopters which should be addressed urgently towards the intervention of SWI. Moreover, unfavourable attitude was observed among a significant percent of non-adopters which is also a crucial fact of the hour. So, to promote the knowledge structure among the nonadopters, a concrete extension programme planning must be constructed and implemented subsequently with a touch of empathy. Besides, inviting a certain transformation in the attitudes of peasants seems to be highly momentous with a view of SWI intervention and the contemporary climate crisis mitigation. For that, a vibrant effort on behalf of public as well as private extension bodies must be put into action along with the clients themselves. There should be 
concerted drive to induce sense of unique venture in farmers through motivational drives.

\section{References}

Anonymous 2009. System of rice intensification annual Report 20082009, AICRP on water Management, WTCER, Bhubnesnwar pp 24.

Doberman A. (2004) A critical assessment of the system or rice intensification (SRI) Agricultural systems 79, 261-281.

Khadka, R. B. and Raut, Prashant (2011).
System of Wheat Intensification (SWI): A new concept on low input technology for increasing wheat yield in marginal land. Mercy Crops Nepal.

Kumari, Maya. Srivastava, A.K. and Sinha, Nidhi. (2010). Extent of knowledge of farm women on nutrition. Indian research journal of Extension Education, 10 (1). 65-68.

Kumar, D. (2002). Attitude of farm women towards dairy cooperative in Bihar. A study in Samastipur district. M.Sc. Thesis R.A.U., Pusa, Samastipur.

\section{How to cite this article:}

Shweta Kumari and Satya Prakash. 2019. Study on Level of Knowledge and Attitude of Farmers towards System of Wheat Intesification (SWI) Technology in Samastipur District of Bihar, India. Int.J.Curr.Microbiol.App.Sci. 8(12): 1047-1054.

doi: https://doi.org/10.20546/ijcmas.2019.812.133 